\title{
Article \\ Super-Toughened Fumed-Silica-Reinforced Thiol-Epoxy Composites Containing Epoxide-Terminated Polydimethylsiloxanes
}

\author{
Goseong Bok, Gayoung Lim, Mingi Kwak and Youngmin Kim * \\ Display Research Center, Korea Electronics Technology Institute, 25 Saenariro, Bundang-gu, \\ Seongnam 13509, Korea; bok0215b@naver.com (G.B.); addzero@kakao.com (G.L.); kwakmg@keti.re.kr (M.K.) \\ * Correspondence: ymkim@keti.re.kr
}

check for updates

Citation: Bok, G.; Lim, G.; Kwak, M.; Kim, Y. Super-Toughened

Fumed-Silica-Reinforced

Thiol-Epoxy Composites

Containing Epoxide-Terminated

Polydimethylsiloxanes. Int. J. Mol.

Sci. 2021, 22, 8097. https://doi.org/

$10.3390 /$ ijms 22158097

Academic Editor: Rajender S. Varma

Received: 9 July 2021

Accepted: 27 July 2021

Published: 28 July 2021

Corrected: 1 August 2022

Publisher's Note: MDPI stays neutral with regard to jurisdictional claims in published maps and institutional affiliations.

Copyright: (c) 2021 by the authors. Licensee MDPI, Basel, Switzerland. This article is an open access article distributed under the terms and conditions of the Creative Commons Attribution (CC BY) license (https:/ / creativecommons.org/licenses/by/ $4.0 /)$.

\begin{abstract}
In response to the demand for high-performance materials, epoxy thermosetting and its composites are widely used in various industries. However, their poor toughness, resulting from the high crosslinking density of the epoxy network, must be improved to expand their application to the manufacturing of flexible products. In this study, ductile epoxy thermosetting was produced using thiol compounds with functionalities of 2 and 3 as curing agents. The mechanical properties of the epoxy were further enhanced by incorporating fumed silica into it. To increase the filler dispersion, epoxide-terminated polydimethylsiloxane was synthesized and used as a composite component. Thanks to the polysiloxane-silica interaction, the nanosilica was uniformly dispersed in the epoxy composites, and their mechanical properties improved with increasing fumed silica content up to $5 \mathrm{phr}$ (parts per hundred parts of epoxy resin). The toughness and impact strength of the composite containing $5 \mathrm{phr}$ nanosilica were $5.17( \pm 0.13) \mathrm{MJ} / \mathrm{m}^{3}$ and $69.8( \pm 1.3) \mathrm{KJ} / \mathrm{m}^{2}$, respectively.
\end{abstract}

Keywords: toughness; impact strength; epoxy composite; epoxide-terminated polydimethylsiloxane; fumed silica

\section{Introduction}

Owing to their high density in crosslinking [1], epoxy thermosetting resins feature excellent mechanical properties, thermal stability, and chemical resistance. Therefore, they are widely used as the materials for light-weighted composites, as well as high-performance adhesives, sealants, and coating materials in various industries from automobile manufacturing to building construction [2-5]. Despite their merits, the brittleness of epoxy resins, stemming from the dense crosslinking, impedes their application in flexible products. To overcome this, much effort has been made to endow epoxy resins with ductility by admixing functionalized liquid rubbers [6]. Given that a crack initiates and its tip meets the rubber particles in an epoxy composite, the stress is concentrated on the rubber particles, leading to their cavitation followed by shear deformation; thus, the applied energy is dissipated, and the fracture toughness of the rubber-modified epoxy is enhanced [7]. The toughness of epoxy resins is also enhanced by incorporating high-molecular-weight components into the epoxy formulation, because of the reduction in crosslinking density [8,9]. Therefore, the increase in deformability of the epoxy composites leads to increased toughness. In this study, a ductile epoxy thermosetting was attained by curing bisphenol A diglycidylether (BPDGE) with a thiol curing agent [10-12]. The thiol curing agent consisted of thiol-based compounds with functionalities of 2 and 3 at the weight ratio of 1 to 1 . Because of the character of the thiol structure [10], the epoxy thermosetting produced by the epoxy-thiol click reaction is ductile (Figure S1 and Table 1). In addition, the mechanical properties of the thermosetting are further optimized by incorporating fillers into it. Given that the mechanical properties of composites are enhanced by the strong interfacial interactions between fillers and the matrix [13], the filler-loading technique is crucial to the realization 
of high-performance composites. Among fillers, nanosilica is widely used to fabricate nanocomposites because of its high reinforcing effectiveness $[14,15]$ and low price. However, the agglomeration of the nanosilica induced by the hydrogen bonding between the silanol groups of silica deteriorates the mechanical properties and processability of the resulting composites. To overcome this, a novel epoxide-terminated polydimethylsiloxane (ep-PDMS) was synthesized and admixed with BPDGE to increase the dispersion efficiency of fumed silica in this study. The interaction between the polysiloxane and silanol groups of silica was previously studied through calculation [16] and experiments [13,17,18]. After confirming by scanning electron microscopy that ep-PDMS enhanced the dispersion of fumed silica in epoxy-based composite, the effect of the fumed silica content on the rheological properties, mechanical properties, impact strength, and thermal stability of the composites was investigated.

\section{Results and Discussion}

Epoxide-terminated polydimethylsiloxane (ep-PDMS) was synthesized by reacting an allyl epoxide with a hydride-terminated PDMS through the platinum-catalyzed hydrosilylation reaction [19] (Figure 1). The completion of the reaction was ascertained by the disappearance of the IR absorption at $2125 \mathrm{~cm}^{-1}$ for Si-H stretching [20] (Figure S2). NMR spectroscopy was conducted to characterize ep-PDMS. In the ${ }^{1} \mathrm{H}$ NMR spectrum of ep$\mathrm{PDMS}$, the proton resonances for $\mathrm{Si}-\mathrm{CH}_{2}$ formed via the hydrosilylation reaction appeared at around $0.6 \mathrm{ppm}$. The proton peaks for oxirane were observed at $2.9 \mathrm{ppm}$ and $3.6 \mathrm{ppm}$, indicating that oxirane was intact despite the hydrosilylation reaction. The presence of

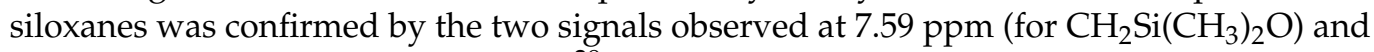
$-21.80 \mathrm{ppm}$ (for $\mathrm{OSi}\left(\mathrm{CH}_{3}\right)_{2} \mathrm{O}$ ) in the ${ }^{29} \mathrm{Si} N M R$ spectrum of ep-PDMS.

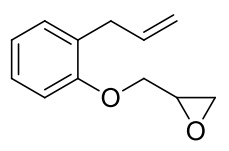

Allyl epoxide

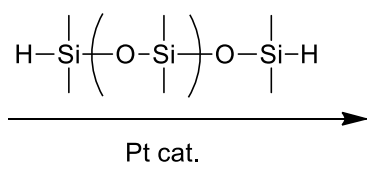

Figure 1. Synthesis of ep-PDMS.

Having produced this compound, the epoxy composition was fabricated by admixing ep-PDMS and BPDGE at the ep-PDMS-to-BPDGE weight ratio of 1 to 9. Then, a stoichiometric amount of thiols and a catalytic amount of 1-methylimidazole (MI) were added to the epoxy resin. The thiol-based curing agent comprised EDT and TMPMP with functionalities of 2 and 3, respectively, at the EDT-to-TMPMP weight ratio of 1 to 1. Because the base-catalyzed epoxy-thiol curing reaction is complex [11], the degree of curing obtained from the kinetic parameters (apparent activation energy, pre-exponential factor, and reaction order) was used to determine the process conditions. The curing behavior of the epoxy/thiol/MI system was investigated by non-isothermal differential scanning calorimetry (DSC) at various heating rates $(\beta)$. When the samples were heated in a differential scanning calorimeter, one exothermic peak stemming from epoxy curing was observed, and the peak temperature $\left(T_{p}\right)$ of the exothermic curve increased with increasing $\beta$ (Figure 2).

After data obtained from the DSC analysis were converted to $\ln \left(\beta / T_{p}{ }^{2}\right)$ and $1 / T_{p}$, the apparent activation energy $\left(E_{a}\right)$ and pre-exponential factor $(\mathrm{A})$ were calculated based on the Kissinger equation (Equation (1)) [21] (Figure 3a). The $E_{a}$ and A values of the epoxy/thiol/MI curing were calculated to be $67.76 \mathrm{KJ} / \mathrm{mol}$ and $2.26 \times 10^{8} \mathrm{~min}^{-1}$ from the slope and y-intercept of the plotting line of $1 / T_{p}$ vs. $\ln \left(\beta / T_{p}{ }^{2}\right)$. The apparent activation energy was also calculated based on the Ozawa equation (Equation (2)) [22] (Figure 3b). 
The linear relation between $1 / T_{p}$ and $\ln (\beta)$ was obtained, and the $E_{a}$ value was calculated to be $70.25 \mathrm{KJ} / \mathrm{mol}$ from the slope of the line.

$$
\begin{gathered}
\ln \left(\frac{\beta}{T_{p}^{2}}\right)=\ln \left(\frac{A R}{E_{a}}\right)-\frac{E_{a}}{R T_{p}} \\
\ln (\beta)=\ln \left(\frac{A E_{a}}{R}\right)-\ln F(a)-5.331-1.052 \frac{E_{a}}{R T} \\
\frac{d(\ln \beta)}{d\left(\frac{1}{T_{p}}\right)}=\frac{-E_{a}}{n R} \\
\alpha=1-\left[1+(n-1) \cdot A \cdot \exp \left(-\frac{E_{a}}{R T}\right) \cdot t\right]^{\frac{1}{1-n}}
\end{gathered}
$$

where $\beta$ is the heating rate, $\mathrm{K} / \mathrm{min} ; T_{p}$ is the exothermic peak temperature, $\mathrm{K} ; E_{a}$ is the apparent activation energy, $\mathrm{J} / \mathrm{mol} ; R$ is the perfect gas constant of $8.314 \mathrm{~J} /(\mathrm{mol} \cdot \mathrm{K})$; and $F(a)$ is a constant function.

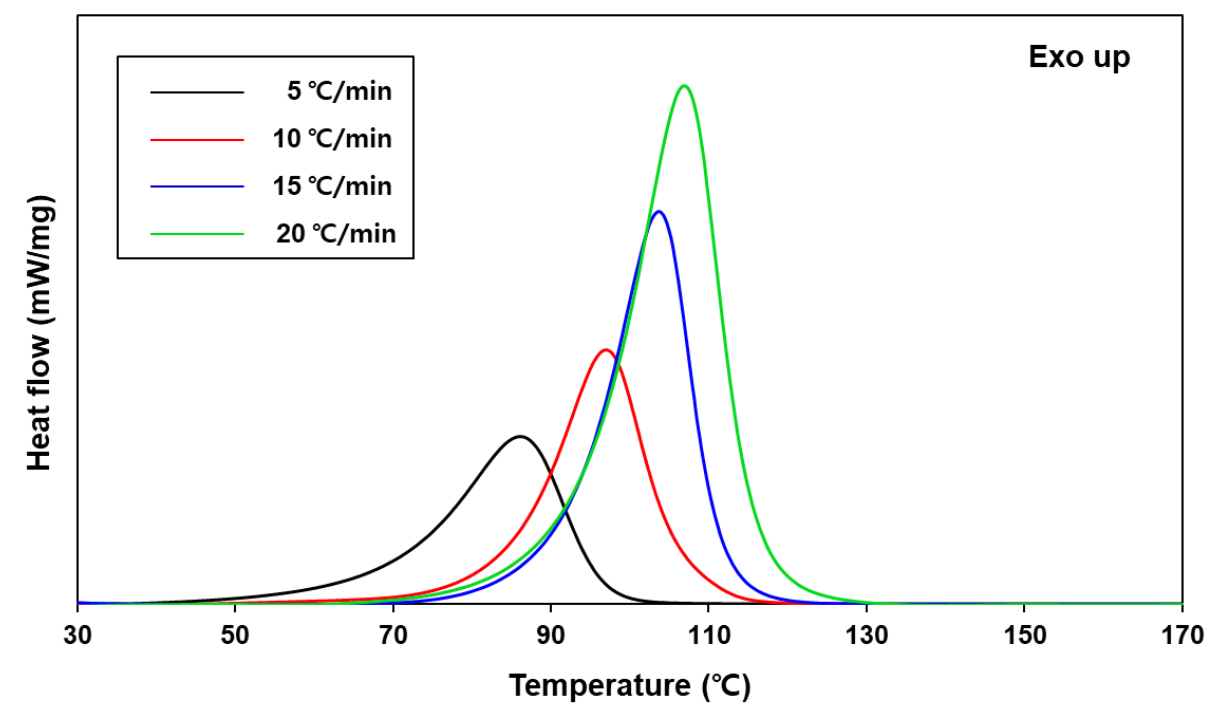

Figure 2. DSC thermograms of epoxy/thiol/MI system obtained at various heating rates.
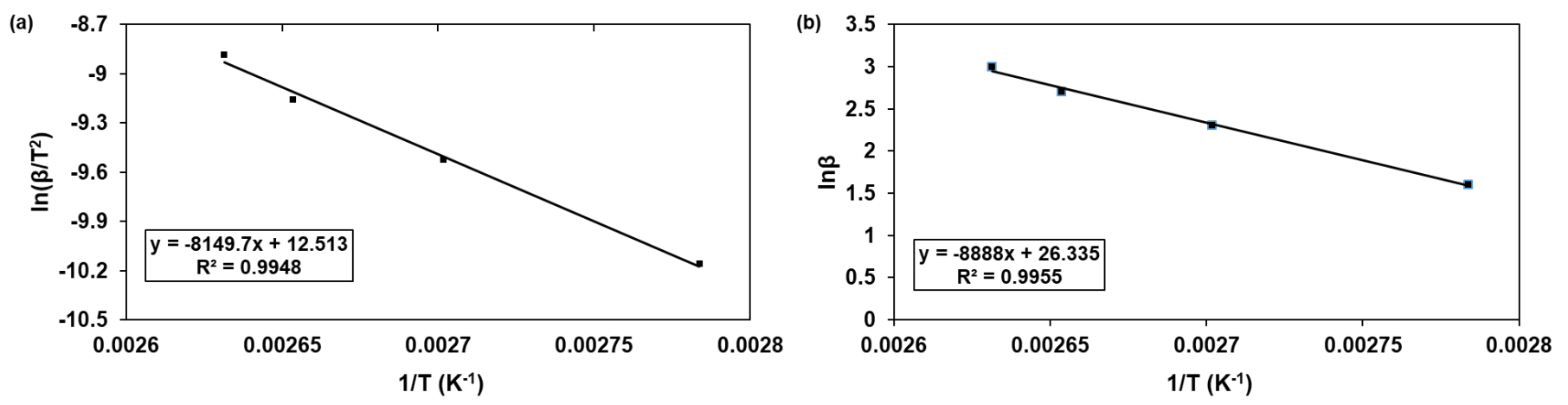

Figure 3. (a) Kissinger plot and (b) Ozawa plot of epoxy/thiol/MI system.

Next, the reaction order $(n)$ of the epoxy/thiol/MI curing was determined as 0.93 using the averaged $E_{a}$ value of $69.00 \mathrm{KJ} / \mathrm{mol}$ according to the simplified Crane equation (Equation (3)) [21]. Finally, the degree of curing $(\alpha)$ of the epoxy/thiol/MI system over time at various temperatures was obtained based on Equation (4) [21], and the results are shown in Figure 4. The curing degree of the epoxy/thiol/MI system increased with 
increasing temperature and extended curing time. For the next step, the epoxy/thiol/MI system was designated as neat epoxy.

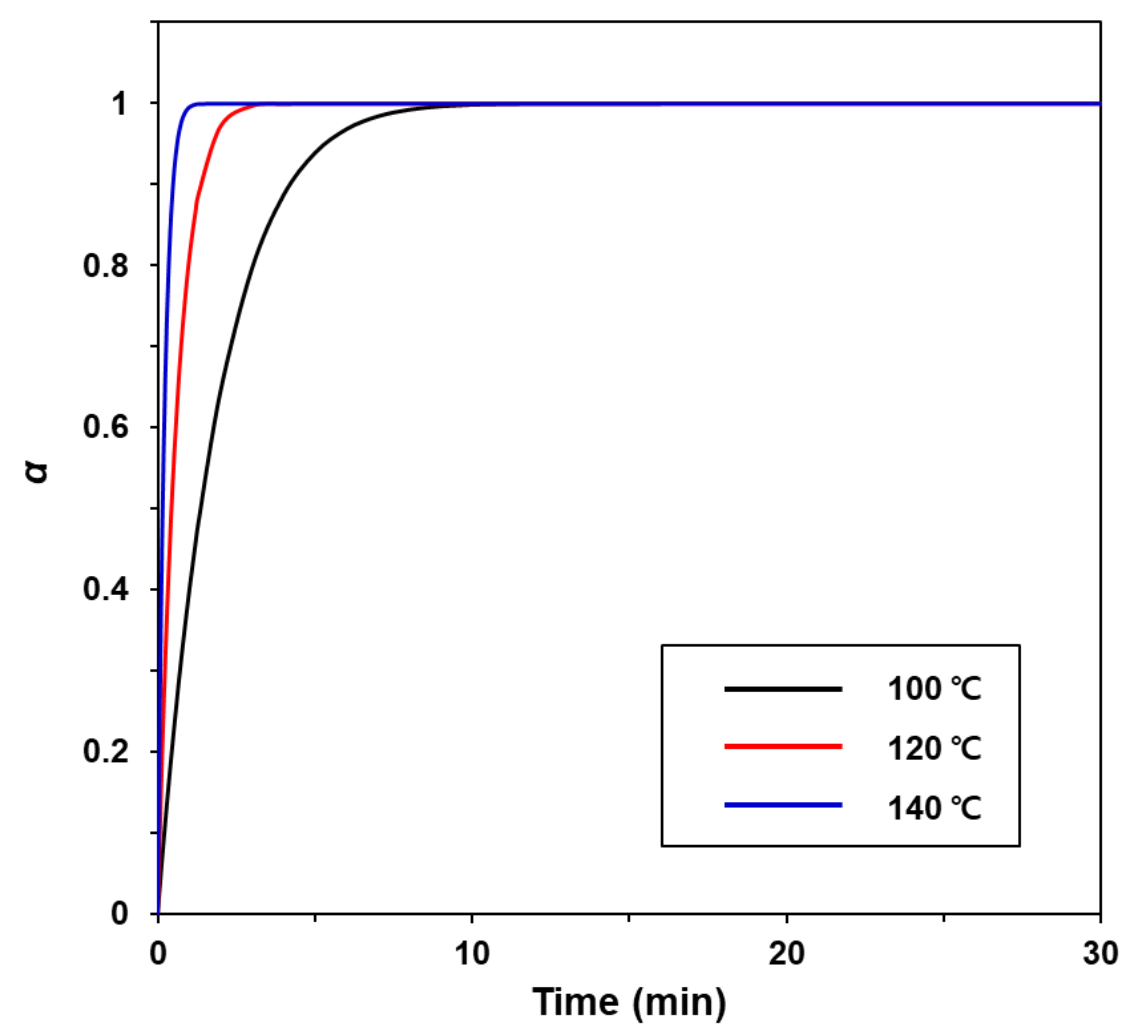

Figure 4. Degree of curing of epoxy/thiol/MI system over time at various temperatures.

Next, nanocomposites were fabricated by mixing neat epoxy and fumed silica. Thanks to the possible interactions between the (Si-O) backbone of ep-PDMS and the silanol groups of the nanosilica, the filler loading reached $7 \mathrm{phr}$ (parts per hundred parts of epoxy) in the composites. The effect of nanosilica loading on the rheological properties of the composites was investigated by measuring the frequency dependence of complex viscosity (Figure 5a). The complex viscosity of the composites increased with increasing nanosilica content. While the complex viscosity of neat epoxy and NC-1 was independent of the frequency (Newtonian flow), that of NC-2, NC-3, and NC-4 decreased with increasing shear rate (shear thinning). This can be explained by the fact that particles align with the flow direction to weaken the particle-particle and polymer-particle interactions at a high shear rate. Therefore, the flow resistance caused by the clusters of fumed silica decreased, leading to low viscosity at a high shear rate $[23,24]$, and this shear-thinning character was more noticeable in the composites with high filler loading. Figure $5 \mathrm{~b}$ shows the loss factor $(\tan \delta)$ of neat epoxy and the composites measured at $1 \mathrm{rad} / \mathrm{s}$. While $\tan \delta$ of NC-4 was less than 1, those of others were higher than 1, indicating that NC-4 behaved like a solid due to the high filler loading. Given that high viscosity deteriorates the processability of composites, the technique to maximize filler loading while maintaining flowability of composites is crucial.

The effect of the nanosilica content on the mechanical properties of the nanocomposites was investigated through a tensile test. Dog-bone-shaped specimens were pulled in the tensile direction until they were broken. The mechanical properties are summarized in Table 1, and stress-strain curves are shown in Figure 6a. While the tensile strength, Young's modulus, and toughness of the composites increased with increasing fumed silica content up to $5 \mathrm{phr}$, elongation at break decreased, though the change in the latter was smaller. Compared to neat epoxy, the strength, modulus, and toughness of NC-3 increased by $76 \%$, $50 \%$, and $44 \%$, respectively, and the elongation decreased by $15 \%$. The toughness of NC-3 
reached $5.17( \pm 0.13) \mathrm{MJ} / \mathrm{m}^{3}$. It is interesting that the strength and toughness of NC-4 were lower than those of NC-3 despite higher filler loading. Given that clusters of fumed silica aggregates were formed with increased filler content, the density in the filler-rich phase was high in NC-4; thus, the applied energy during the tensile test was concentrated on the fillers and not transferred to the matrix, causing fracture to occur at the low elongation.
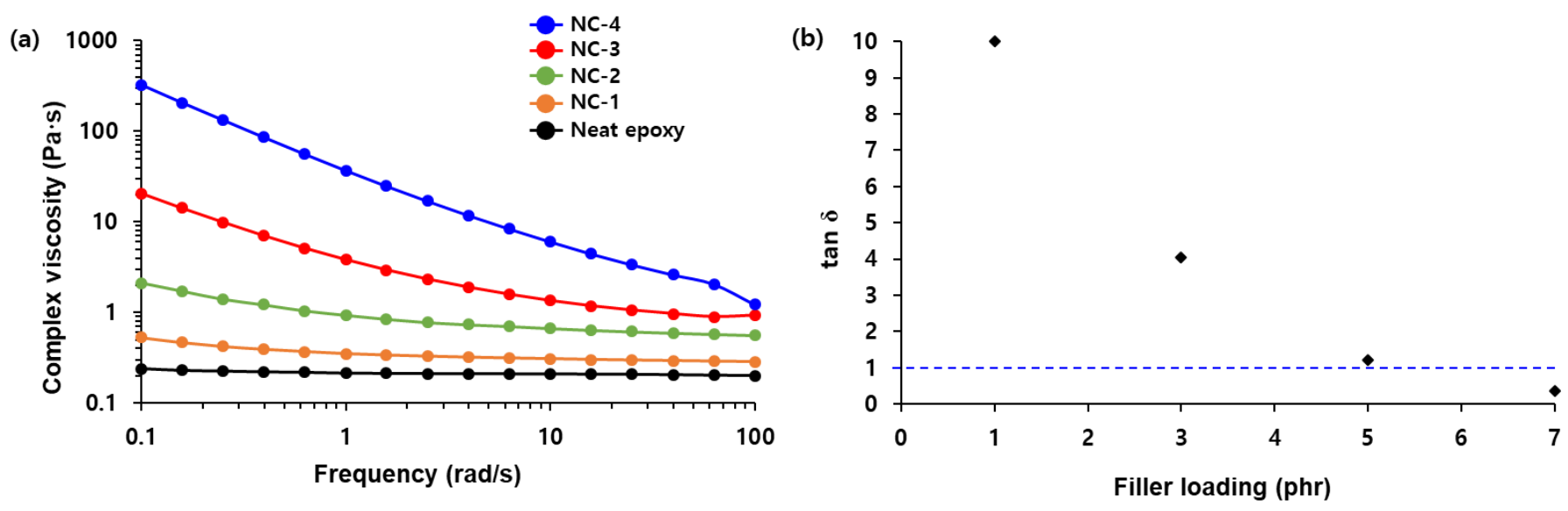

Figure 5. (a) Shear-rate dependency of the complex viscosity of neat epoxy and the fumed silica composites and (b) the filler loading dependence of $\tan \delta$ measured at $1 \mathrm{rad} / \mathrm{s}$.

Table 1. Mechanical properties of neat epoxy and nanocomposites.

\begin{tabular}{cccccc}
\hline & Neat Epoxy & NC-1 & NC-2 & NC-3 & NC-4 \\
\hline Tensile strength $(\mathrm{MPa})$ & $4.2 \pm 0.3$ & $4.8 \pm 0.6$ & $5.7 \pm 0.6$ & $7.4 \pm 0.3$ & $5.7 \pm 0.5$ \\
Elongation at break $(\%)$ & $156 \pm 8$ & $147 \pm 20$ & $142 \pm 2$ & $133 \pm 3$ & $99 \pm 11$ \\
Young's modulus $(\mathrm{MPa})$ & $10.3 \pm 0.5$ & $11.3 \pm 0.3$ & $13.9 \pm 0.8$ & $15.4 \pm 1.1$ & $16.7 \pm 0.2$ \\
Toughness $\left(\mathrm{MJ} / \mathrm{m}^{3}\right)$ & $3.6 \pm 0.02$ & $3.8 \pm 0.88$ & $4.35 \pm 0.42$ & $5.17 \pm 0.13$ & $3.14 \pm 0.15$ \\
Impact strength $\left(\mathrm{KJ} / \mathrm{m}^{2}\right)$ & $39.9 \pm 8.5$ & $49.7 \pm 4.3$ & $60.7 \pm 3.4$ & $69.8 \pm 1.3$ & $26.4 \pm 1.8$ \\
\hline
\end{tabular}
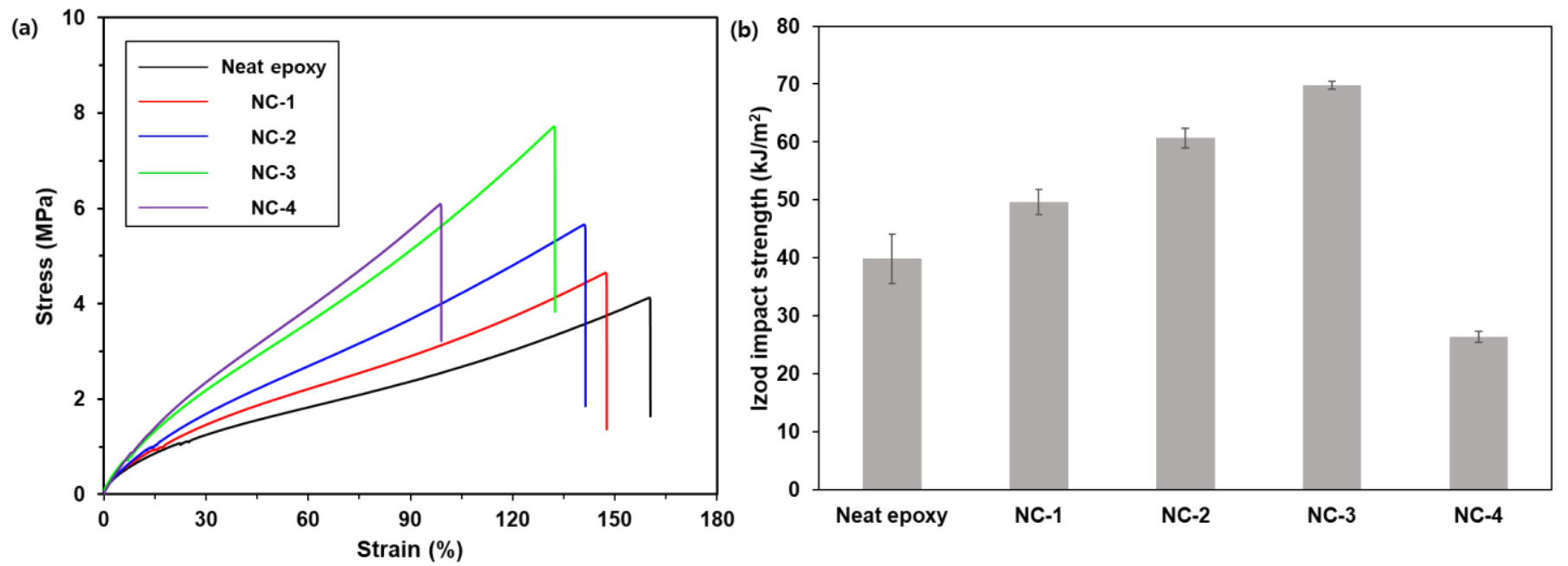

Figure 6. (a) Stress-strain curves of neat epoxy and nanocomposites and (b) Izod impact strength of nanocomposites.

Next, to investigate the effect of ep-PDMS on the mechanical properties of the composites, a control composite containing 5 phr fumed silica was fabricated without ep-PDMS. The mechanical properties of the control sample are summarized in Table S1, and its stressstrain is shown in Figure S3. Compared to the control composite, the strength, elongation, and toughness of NC-3 were higher by $28 \%, 43 \%$, and $53 \%$, respectively, with the same filler content, suggesting that ep-PDMS is effective to disperse fumed silica in epoxy resins. The 
poor dispersion of fumed silica in the control sample was confirmed by the FESEM images (Figure S4). Unlike NC-3, micron-sized clusters of fumed silica were clearly observed in the control composite.

The effect of fumed silica content on the impact strength of composites was investigated through a notched Izod impact test. Rectangular specimens with a V-shaped notch were struck by a hammer, and the absorbed energy was recorded. The results are summarized in Table 1 and shown in Figure 6b. The impact strength of the composites increased with an increasing nanosilica content ranging from 0 to $5 \mathrm{phr}$. It is interesting that the specimens were partially broken after the Izod impact test, indicating that they were ductile. Compared to neat epoxy, the impact strength of NC-3 increased by $75 \%$, and this enhancement was attributed to the strong filler-matrix interaction with the help of ep-PDMS. It should be noted that the impact strength of NC-3 was about $70 \mathrm{KJ} / \mathrm{m}^{2}$, and this high value is rare for epoxy composites [25-30] (Figure S5) and comparable to those of super-toughened poly(lactic acid) blends with impact strength higher than $53 \mathrm{KJ} / \mathrm{m}^{2}$ [31] On the contrary, the impact strength of NC-4 was even lower than that of neat epoxy by $34 \%$, implying that the presence of filler-rich phase led to severe deterioration in the impact strength of the composites despite high filler loading. Given that NC-4 was completely broken after the Izod impact test, whereas other samples were partially broken, the clusters of fumed silica endowed NC-4 with brittleness. The surface morphologies of fractured NC-3 and NC-4 after the Izod impact test were analyzed by FESEM (Figure 7). While the surface of NC-3 was smooth, filler-rich phase with bulging nanosilica was observed on that of NC-4.

(a)

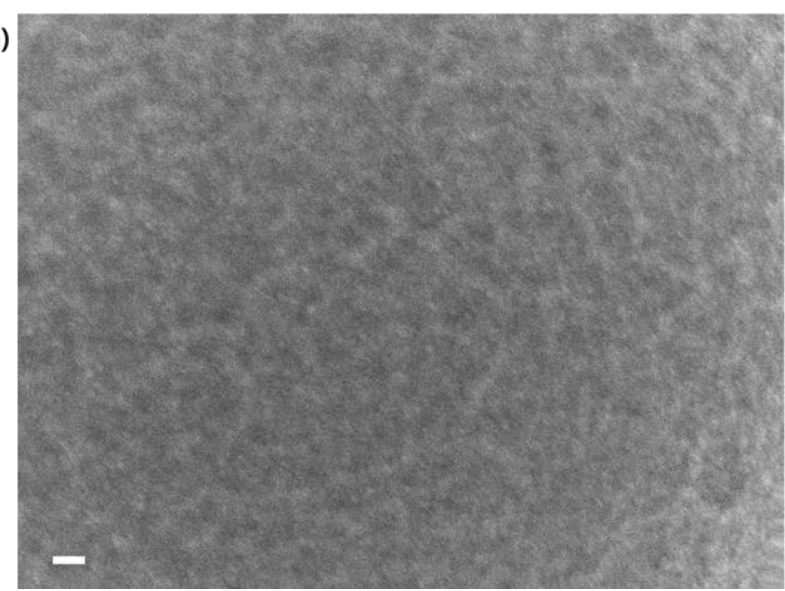

(b)

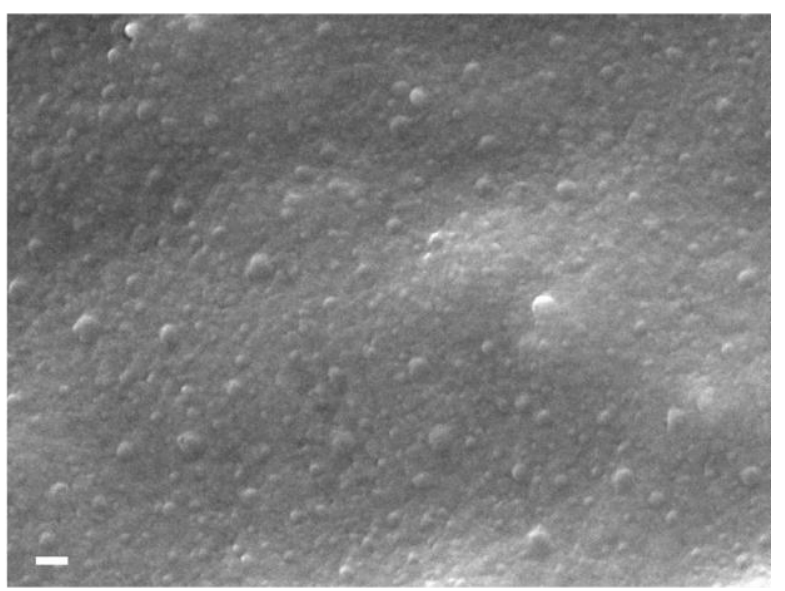

Figure 7. FESEM images of the fractured surface of (a) NC-3 and (b) NC-4 after a notched Izod impact test. A scale bar represents $100 \mathrm{~nm}$.

Next, the thermal stability of the neat epoxy and the nanocomposites was investigated by thermogravimetric analysis (TGA) in temperatures ranging from $50{ }^{\circ} \mathrm{C}$ to $450{ }^{\circ} \mathrm{C}$ (Figure 8). All specimens were stable up to $300^{\circ} \mathrm{C}$, at which the weight loss percentage was less than $5 \%$. In addition, the amount of the residue at $450{ }^{\circ} \mathrm{C}$ increased with increasing filler loading in the composites. DSC measurements of them were carried out to determine the glass transition temperature ( $\mathrm{Tg}$ ), and the results are summarized in Table 2 . The $\mathrm{Tg}$ values of the composites also increased with increasing fumed silica loading, though the change was little. 


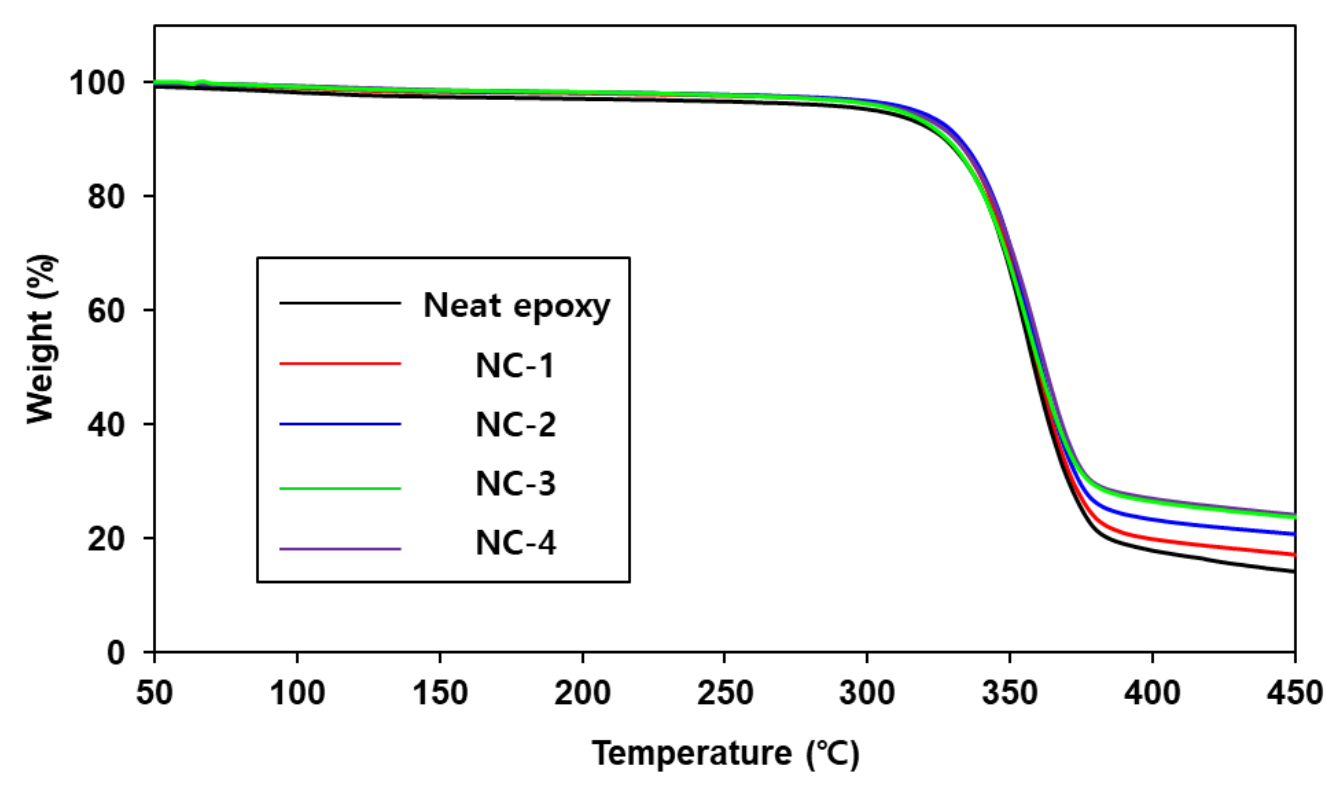

Figure 8. TGA thermograms of neat epoxy and nanocomposites.

Table 2. Glass transition temperature of neat epoxy and nanocomposites.

\begin{tabular}{cccccc}
\hline & Neat Epoxy & NC-1 & NC-2 & NC-3 & NC-4 \\
\hline $\operatorname{Tg}\left({ }^{\circ} \mathrm{C}\right)$ & 11.24 & 12.30 & 12.31 & 12.45 & 12.75 \\
\hline
\end{tabular}

\section{Materials and Methods}

\subsection{Materials}

Bisphenol A diglycidyl ether (BPDGE, EEW = $190 \mathrm{~g} / \mathrm{eq}$ ) was purchased from Kukdo Chemical Co., Ltd (Seoul, Korea). 1-methylimidazole (MI) was purchased from Tokyo Chemical Industry Co., Ltd. (Tokyo, Japan). Hydride-terminated poly(dimethylsiloxane) (Mn 580, h-PDMS), platinum(0)-1,3-divinyl-1,1,3,3-tetramethyldisiloxane complex solution in xylene (Pt cat), 2,2'-(ethylenedioxy)diethanethiol (EDT), trimethylolpropane tirs(3mercaptopropioante) (TMPMP), and anhydrous magnesium sulfate were purchased from Sigma-Aldrich Korea Ltd. (Yongin, Korea). Toluene was purchased from Samchun Chemical (Seoul, Korea). Fumed silica (K-200) of silica aggregates consisting of 7 to 40 nm primary particles was purchased from OCI (Seoul, Korea). All chemicals were used as received without purification.

\subsection{Instrumentation}

The ${ }^{1} \mathrm{H}$ NMR, ${ }^{13} \mathrm{C}$ NMR, and ${ }^{29}$ Si NMR spectra were measured on an NMR spectrometer equipped with Bruker Top Spin 3.2 software (Ascend ${ }^{\text {TM }}$ 400, Bruker, Madison, WI, USA). The Fourier transform infrared (FTIR) spectra in the range from 500 to $4000 \mathrm{~cm}^{-1}$ were obtained through the attenuated total reflectance method using an FTIR spectrophotometer (IRAffinity-1S, Shimadzu, Kyoto, Japan). A tensile test was carried out using a universal testing machine (HZ-1003A/B(1T), MMS Tech, Bucheon, Korea). A non-isothermal DSC analysis was performed using a DSC-4000 (PerkinElmer, Waltham, MA, USA). Izod impact strength was measured using an Izod impact tester (KP-M3940D, KIPAE). The surface morphologies of the fractured composites were analyzed using a field emission scanning electron microscope (FESEM).

\subsection{Synthesis of ep-PDMS}

An allyl epoxide was synthesized following the previously reported method [32]. A flask was charged with allyl epoxide $(6.0 \mathrm{~g}, 31.58 \mathrm{mmol})$, h-PDMS (9.16 g, $15.78 \mathrm{mmol}), \mathrm{Pt}$ cat $(0.16 \mathrm{~g})$, and toluene $(15.16 \mathrm{~g})$. This solution was heated at $95^{\circ} \mathrm{C}$ using an oil bath. After 
$12 \mathrm{~h}$ stirring, the mixture was poured into a separatory funnel and sequentially washed with deionized water and brine solution. The organic layer was separated and dried over anhydrous magnesium sulfate. The organic layer was filtered through celite, and all volatiles were removed from the filtrate under reduced pressure to produce ep-PDMS in a brown liquid with the viscosity of $72 \mathrm{mPa} \cdot \mathrm{s}$ at $25^{\circ} \mathrm{C}$. The epoxy equivalent of ep-PDMS was calculated as $480 \mathrm{~g} / \mathrm{eq}$.

${ }^{1} \mathrm{H}$ NMR $\left(400 \mathrm{MHz}, \mathrm{CDCl}_{3}\right)$ data: $\delta: 7.15-7.13(\mathrm{~m}$, aromatic ring), $6.93-6.90(\mathrm{t}$, aromatic ring), 6.83-6.81 (d, aromatic ring), 4.25-3.80 (d, O- $\left.\mathrm{CH}_{2}\right), 3.66-3.62(\mathrm{~m}$, glycidyl), 2.90-2.88 (d, glycidyl), 2.78-2.65 (t, $\left.\mathrm{ArCH}_{2}\right), 1.66\left(\mathrm{~m}, \mathrm{SiCH}_{2} \mathrm{CH}_{2}\right), 0.75-0.55\left(\mathrm{t}, \mathrm{SiCH}_{2}\right)$, $0.30-0.00\left(\mathrm{~m}, \mathrm{SiCH}_{3}\right)$.

${ }^{13} \mathrm{C}$ NMR $\left(100 \mathrm{MHz}, \mathrm{CDCl}_{3}\right)$ data: $\delta: 156.4,131.5,130.1,126.9,121.0,111.4,68.6,50.4$, $44.6,34.0,23.7,18.4,0.99,0.79$.

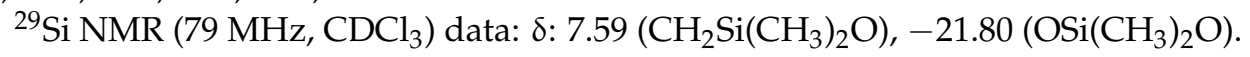

\subsection{Preparation of Compositions of Neat Epoxy and Nanocomposites}

Each composition of neat epoxy and nanocomposites is summarized in Table 3. A $50 \mathrm{~mL}$ vial was charged with BPDGE, ep-PDMS, and fumed silica, and the mixture was subject to an ultra-sonication treatment. After $2 \mathrm{~h}, \mathrm{EDT}$, TMPMP, and MI were added to the mixture. Each composition was agitated using a vortex mixer for $20 \mathrm{~min}$ and degassed under reduced pressure.

Table 3. The compositions of neat epoxy and nanocomposites.

\begin{tabular}{cccccc}
\hline & Neat Epoxy & NC-1 & NC-2 & NC-3 & NC-4 \\
\hline BPDGE (g) & 9 & 9 & 9 & 1 & 1 \\
ep-PDMS (g) & 1 & 1 & 2.67 & 2.67 & 1 \\
EDT (g) & 2.67 & 2.67 & 2.67 & 2.67 & 2.67 \\
TMPMP (g) & 2.67 & 2.67 & 0.11 & 0.11 & 2.67 \\
MI (g) & 0.11 & 0.11 & 0.3 & 0.5 & 0.11 \\
Fumed silica (g) & 0 & 1 & 3 & 5 & 7 \\
Filler loading (phr) & a & 0 & 0.1 & & 7 \\
\hline
\end{tabular}

${ }^{a}$ phr-parts per hundred parts of epoxy resin.

\subsection{Tensile Test}

The as-prepared compositions were poured into a dog-bone-shaped Teflon mold and heated at $140{ }^{\circ} \mathrm{C}$ for $1 \mathrm{~h}$. Then, the specimens were placed in a tensile tester and pulled along the z-axis until they were broken.

\subsection{Izod Impact Strength Test}

Izod impact strength was measured following an ASTM D256 standard test method using a pendulum- $C$ type hammer. The as-prepared compositions of neat epoxy and nanocomposites were poured into a Teflon mold with dimensions of $63.5 \mathrm{~mm} \times 12.7 \mathrm{~mm}$ $\times 6.35 \mathrm{~mm}$ (width $\times$ length $\times$ thickness) and kept at $140{ }^{\circ} \mathrm{C}$ in a convection oven. After 1 hour, all specimens were cooled to room temperature, and a V-notch with a depth of $2.54 \mathrm{~mm}$ was made at the center of them using a cutter.

\section{Conclusions}

In this work, epoxide-terminated PDMS (ep-PDMS) was synthesized and used to produce thiol-epoxy composites containing fumed silica. Thanks to the polysiloxanesilica interaction, the mechanical properties of the epoxy composites containing ep-PDMS improved with increasing fumed silica content up to $5 \mathrm{phr}$. The toughness and impact strength of NC-3 were $5.17( \pm 0.13) \mathrm{MJ} / \mathrm{m}^{3}$ and $69.8( \pm 1.3) \mathrm{KJ} / \mathrm{m}^{2}$, respectively. The mechanical properties of the composite without ep-PDMS containing $5 \mathrm{phr}$ nanosilica were inferior to those of NC-3 despite having the same filler content because of the poor 
dispersion of fumed silica. In conclusion, the employment of ep-PDMS is expected to be an effective way to realize super-toughened fumed-silica epoxy composites.

Supplementary Materials: The following are available online at https:/ /www.mdpi.com/article/10 $.3390 /$ ijms22158097/s1.

Author Contributions: Conceptualization, M.K.; validation, G.B.; formal analysis, G.L.; investigation, G.B.; writing-original draft preparation, Y.K.; supervision, Y.K. All authors have read and agreed to the published version of the manuscript.

Funding: This work was supported by the Ministry of Trade, Industry, and Energy (MOTIE, Korea) (grant number 20006956, Development of underfill material and package module with high thermalshock ( $\geq 2000$ cycles) and mechanical drop reliability for mobile applications). Further support was provided by the Ministry of Trade, Industry, and Energy (MOTIE, Korea) (grant number 20013097, Development of technology for optimizing manufacturing thermally conductive component using spherical aluminum oxide).

Institutional Review Board Statement: Not applicable.

Informed Consent Statement: Not applicable.

Data Availability Statement: Data sharing not applicable.

Conflicts of Interest: The authors declare no conflict of interest.

\section{References}

1. Domun, N.; Hadavinia, H.; Zhang, T.; Sainsbury, T.; Liaghat, G.; Vahid, S. Improving the fracture toughness and the strength of epoxy using nanomaterials-a review of the current status. Nanoscale 2015, 7, 10294-10329. [CrossRef]

2. Gu, H.; Ma, C.; Gu, J.; Guo, J.; Yan, X.; Huang, J.; Zhang, Q.; Guo, Z. An overview of multifunctional epoxy nanocomposites. J. Mater. Chem. C 2016, 4, 5890-5906. [CrossRef]

3. Jojibabu, P.; Zhang, Y.; Prusty, B.G. A review of research advances in epoxy-based nanocomposites as adhesive materials. Int. J. Adhes. Adhes. 2020, 96, 102454. [CrossRef]

4. Balguri, P.K.; Samuel, D.H.; Thumu, U. A review on mechanical properties of epoxy nanocomposites. Mater. Today Proc. 2021, 44, 346-355. [CrossRef]

5. Frigione, M.; Lettieri, M. Recent Advances and Trends of Nanofilled/Nanostructured Epoxies. Materials 2020, 13, 3415. [CrossRef] [PubMed]

6. Garg, A.C.; Mai, Y.-W. Failure mechanisms in toughened epoxy resins-A review. Compos. Sci. Technol. 1988, 31, 179-223. [CrossRef]

7. Bagheri, R.; Marouf, B.T.; Pearson, R.A. Rubber-Toughened Epoxies: A Critical Review. Polym. Rev. 2009, 49, 201-225. [CrossRef]

8. Levita, G.; De Petris, S.; Marchetti, A.; Lazzeri, A. Crosslink density and fracture toughness of epoxy resins. J. Mater. Sci. 1991, 26, 2348-2352. [CrossRef]

9. Ratna, D.; Banthia, A.K. Rubber toughened epoxy. Macromol. Res. 2004, 12, 11-21. [CrossRef]

10. Guzmán, D.; Ramis, X.; Francos, X.F.; Serra, A. New catalysts for diglycidyl ether of bisphenol A curing based on thiol-epoxy click reaction. Eur. Polym. J. 2014, 59, 377-386. [CrossRef]

11. Konuray, A.O.; Fernández-Francos, X.; Ramis, X. Analysis of the reaction mechanism of the thiol-epoxy addition initiated by nucleophilic tertiary amines. Polym. Chem. 2017, 8, 5934-5947. [CrossRef]

12. Konuray, O.; Fernández-Francos, X.; De la Flor, S.; Ramis, X.; Serra, À. The Use of Click-Type Reactions in the Preparation of Thermosets. Polymers 2020, 12, 1084. [CrossRef] [PubMed]

13. Bok, G.; Lim, G.; Park, K.; Kim, Y. Mechanical properties and fracture toughness of fumed silica epoxy composites containing glycidyl terminated polysiloxanes. Ceram. Int. 2021. [CrossRef]

14. Jo, H.S.; Lee, G.W. Investigation of Mechanical and Thermal Properties of Silica-Reinforced Epoxy Composites by Using Experiment and Empirical Model. Mater. Today Proc. 2017, 4, 6178-6187. [CrossRef]

15. Li, H.; Liu, F.; Tian, H.; Wang, C.; Guo, Z.; Liu, P.; Peng, Z.; Wang, Q. Synergetic enhancement of mechanical and electrical strength in epoxy/silica nanocomposites via chemically-bonded interface. Compos. Sci. Technol. 2018, 167, 539-546. [CrossRef]

16. Stricher, A.M.; Rinaldi, R.G.; Barrès, C.; Ganachaud, F.; Chazeau, L. How I met your elastomers: From network topology to mechanical behaviours of conventional silicone materials. RSC Adv. 2015, 5, 53713-53725. [CrossRef]

17. Fragiadakis, D.; Pissis, P. Glass transition and segmental dynamics in poly(dimethylsiloxane)/silica nanocomposites studied by various techniques. J. Non-Cryst. Solids 2007, 353, 4344-4352. [CrossRef]

18. Paquien, J.-N.; Galy, J.; Gérard, J.-F.; Pouchelon, A. Rheological studies of fumed silica-polydimethylsiloxane suspensions. Colloids Surf. A Physicochem. Eng. Asp. 2005, 260, 165-172. [CrossRef]

19. Speier, J.L.; Zimmerman, R.; Webster, J. The Addition of Silicon Hydrides to Olefinic Double Bonds. Part I. The Use of Phenylsilane, Diphenylsilane, Phenylmethylsilane, Amylsilane and Tribromosilane. J. Am. Chem. Soc. 1956, 78, 2278-2281. [CrossRef] 
20. Bok, G.; Lee, C.-J.; Lee, H.; Kim, Y. Fabrication of flexible electrodes using peelable pressure-sensitive adhesives containing methacrylic-modified cyclic siloxanes. React. Funct. Polym. 2021, 165, 104940. [CrossRef]

21. Ding, J.; Peng, W.; Luo, T.; Yu, H. Study on the curing reaction kinetics of a novel epoxy system. RSC Adv. 2016, 7, 6981-6987. [CrossRef]

22. Zheng, T.; Wang, X.; Lu, C.; Zhang, X.; Ji, Y.; Bai, C.; Chen, Y.; Qiao, Y. Studies on Curing Kinetics and Tensile Properties of Silica-Filled Phenolic Amine/Epoxy Resin Nanocomposite. Polymers 2019, 11, 680. [CrossRef] [PubMed]

23. Ramesh, S.; Liew, C.W. Rheological characterizations of ionic liquid-based gel polymer electrolytes and fumed silica-based composite polymer electrolytes. Ceram. Int. 2012, 38, 3411-3417. [CrossRef]

24. Adesina, A.A.; Nasser, M.; Teixeira, P.; Hilliou, L.; Covas, J.A.; Hussein, I.A. Rheology of organoclay assisted extrusion of HDPE using Particle Image Velocimetry. Chem. Eng. Res. Des. 2015, 100, 113-125. [CrossRef]

25. Mylsamy, B.; Palaniappan, S.K.; Subramani, S.P.; Pal, S.K.; Aruchamy, K. Impact of nanoclay on mechanical and structural properties of treated Coccinia indica fibre reinforced epoxy composites. J. Mater. Res. Technol. 2019, 8, 6021-6028. [CrossRef]

26. Aruchamy, K.; Subramani, S.P.; Palaniappan, S.K.; Sethuraman, B.; Kaliyannan, G.V. Study on mechanical characteristics of woven cotton/bamboo hybrid reinforced composite laminates. J. Mater. Res. Technol. 2020, 9, 718-726. [CrossRef]

27. Li, Y.; Gao, J.; Li, X.; Xu, X.; Lu, S. High Mechanical and Thermal Properties of Epoxy Composites with Liquid Crystalline Polyurethane Modified Graphene. Polymers 2018, 10, 485. [CrossRef]

28. Xiao, X.; Lu, S.; Qi, B.; Zeng, C.; Yuan, Z.; Yu, J. Enhancing the thermal and mechanical properties of epoxy resins by addition of a hyperbranched aromatic polyamide grown on microcrystalline cellulose fibers. RSC Adv. 2014, 4, 14928-14935. [CrossRef]

29. Fei, X.; Wei, W.; Tang, Y.; Zhu, Y.; Luo, J.; Chen, M.; Liu, X. Simultaneous enhancements in toughness, tensile strength, and thermal properties of epoxy-anhydride thermosets with a carboxyl-terminated hyperbranched polyester. Eur. Polym. J. 2017, 90, 431-441. [CrossRef]

30. Pan, L.; Lu, S.; Xiao, X.; He, Z.; Zeng, C.; Gao, J.; Yu, J. Enhanced mechanical and thermal properties of epoxy with hyperbranched polyester grafted perylene diimide. RSC Adv. 2014, 5, 3177-3186. [CrossRef]

31. Nagarajan, V.; Mohanty, A.K.; Misra, M. Perspective on Polylactic Acid (PLA) based Sustainable Materials for Durable Applications: Focus on Toughness and Heat Resistance. ACS Sustain. Chem. Eng. 2016, 4, 2899-2916. [CrossRef]

32. Capote, M.; Harrison, E.; Lee, Y.-J.; Lenos, H. High Performance Cyanate-Bismaleimide-Epoxy Resin Compositions for Printed Circuits and Encapsulants. WIPO WO2000071614A1, 30 November 2000. 